\title{
Self-reported Occupational Health Problems among Libyan Dentists
}

\author{
${ }^{1}$ Arheiam Arheiam, ${ }^{2}$ Mohamed Ingafou
}

\section{ABSTRACT}

Objectives: To investigate the prevalence of the most common occupation-related health problems as well as factors associated with their incidence among dental practitioners.

Materials and methods: A cross-sectional, questionnairebased survey of Libyan dental practitioners. Participants provided information regarding their experience of occupationally related problems they encountered over the past 12 months which included inquiries about musculoskeletal pain, percutaneous injuries, allergy, eye and sight problems, and hearing problems.

Results: Musculoskeletal problems were the most frequently reported $(48.2 \%)$, followed by percutaneous injuries (35\%), eye problems $(22 \%)$, allergy $(11 \%)$ and hearing problems (7.6\%). Musculoskeletal problems were significantly higher among dentists who work in private sector, full timer as well as those who prefer to work in a sitting position $(p=0.021$, 0.027 and 0.008 , respectively). Practitioners with less than 5 years in service reported significantly higher percentage of percutaneous injuries $(p=0.027)$ than their senior counterparts, whereas practitioners who spent more than 10 years in service were more likely to suffer from visual disturbances $(p=0.033)$.

Conclusion: The findings of this study indicate that musculoskeletal problems and percutaneous injuries are the most commonly reported occupational health problems among dentists, whereas allergic reactions and hearing problems are the least reported ones.

Clinical significance: Dentists should use alternate working positions to minimise musculoskeletal problems and adopt more effective strategies to prevent percutaneous injuries particularly among novices.

Keywords: Occupation, Hazards, Dentists, Symptoms, Selfreported.

How to cite this article: Arheiam A, Ingafou M. Self-reported Occupational Health Problems among Libyan Dentists. J Contemp Dent Pract 2015;16(1):31-35.

Source of support: Nil

Conflict of interest: None

\footnotetext{
${ }^{1}$ Department of Community and Preventive Dentistry, Benghazi University, Benghazi, Libya

${ }^{2}$ Department of Oral Medicine, Benghazi University, Benghazi Libya

Corresponding Author: Arheiam Arheiam, Lecturer Department of Community and Preventive Dentistry, Benghazi University, Benghazi, Libya, Phone: 00218924126742, e-mail: arheiam@yahoo.com
}

\section{INTRODUCTION}

Modern dentistry has been described as presumably among the least risky of all occupations. ${ }^{1}$ However, some issues associated with working environment and practices as well as the exposure to dental materials and several infectious diseases may still stand to challenge this status. ${ }^{2}$ Stress, tension, and postural habits accompanying the practice of dentistry, can contribute to back and neck problems and certainly pose significant occupational health issue for both dentists and dental hygienists, as they often need to seek medical treatment for these problems. ${ }^{3}$ However, some occupational hazards are not specific to dentistry alone and any member of the public can get similar symptoms, and may be influenced by age, gender, work station design and geographical factors. ${ }^{4}$

A considerable amount of literature has been published on occupational health problems among dental practitioners. ${ }^{5-8}$ These studies have reported variable prevalence and incidence rates of occupational hazards associated with dentistry. The most commonly reported occupational health complaints by many practicing dentists are musculoskeletal problems, percutaneous injuries, allergic reactions, eye and hearing problems and exposure to different dental materials and biological agents. ${ }^{2}$ In one study that extended over 9 years, the sharp injuries accounted for more than half of occupational incidents among dental personnel. ${ }^{9}$

The above discussion raises an interesting question concerning the prevalence and predisposing factors of work-related health problems among Libyan dental practitioners. To date no research in Libya has explored any of the various aspects of occupational hazards in dental practice. This study was set out to explore the prevalence of common occupational health problems among Libyan dentists.

\section{MATERIALS AND METHODS}

This study is cross-sectional, questionnaire-based survey of dental practitioners from different parts of Libya. According to the most recent official data, the total population of Libya is approaching six million inhabitants, and the dentist to population ratio is at an estimated value of 6:10,000 inhabitants in $2013 .{ }^{10}$ The participants were recruited from the attendees of the National Dental 
Forum held in the state's capital (Tripoli) June 2013. A total of 450 practicing dentists were invited to participate in this survey, of which there were 378 respondents (response rate: $84 \%$ ). Thirty-eight newly graduated dentists (spent less than 1 year in service) were excluded from this survey, so the present analysis is based upon information collected from 340 participants who had completed the questionnaire on all the variables selected for analysis.

The data were collected using a self-administrated questionnaire, which was distributed in-person during the National Dental Conference. Participants were approached by the researchers and invited to participate and a copy of the self-administered questionnaire, written in simple English language, was handed over and the researchers returned the day after collection. The questionnaire was pretested being clear and understandable among a group of 20 dentists working in the faculty of dentistry, Benghazi University. As no changes to the questionnaire form were actually needed during the pilot study, the questionnaires completed in pilot study were included in the final study sample (all questionnaires were completed once by the participants). The participants were asked to provide information about their demographic (age and sex) and professional characteristics, such as the type of practice sector (public or private), work pattern (part time or full time), the level of dental education (University degree, or higher degrees), the number of years in dental practice, and the preferred working position (sitting, standing or mixed). The participants were also asked to list their occupational health problem that they have experienced

Table 1: Characteristics of the study sample $(n=340)$

\begin{tabular}{lll}
\hline Variables & $N$ & $\%$ \\
\hline Sex & 165 & 48.5 \\
Men & 175 & 51.5 \\
Women & & \\
Dental education & 217 & 63.6 \\
BDS & 124 & 36.4 \\
Higher degree & & \\
Practice sector & 160 & 47.2 \\
Public & 180 & 52.8 \\
Private & & \\
Years of service & 90 & 26.4 \\
1-5 years & 110 & 32.3 \\
6-10 years & 140 & 41.3 \\
$>10$ years & & \\
Work mode & 163 & 47.9 \\
Part time & 177 & 52.1 \\
Full time & & \\
Preferable working position & 26 & 7.6 \\
Sitting & 199 & 58.5 \\
Standing & 115 & 33.8 \\
Both & & \\
\hline
\end{tabular}

over the past year. The instrument was consisted of five items enquiring about the dentists' experiences of musculoskeletal problem (backache, headache, and shoulder, neck, facial, scalp, hands and wrist pain), Percutaneous injuries (needle stick injuries and injuries from explorers, matrix bands, burs, scalars, suture needles, exodontia elevators, cutters and dental wiring), allergic reactions to (latex gloves, paper face masks, acrylic powder, plastic eyeglasses and dental materials), hearing problems (reduced hearing, earaches, tinnitus, vertigo and other hearing problems), and eye problems (short sight, long sight, stigmatism, unclear sight, eye fatigue and ocular injuries). Their answers were given on 'yes' or 'no' question pattern indicating whether or not they have experienced at least one occupational health problem in the past year.

This research has been conducted in full accordance with the World Medical Association Declaration of Helsinki. The study protocol was approved by the Benghazi University. Formal permissions were obtained from local authorities and written informed consent was obtained from participants, which is implied by completing the questionnaires.

Data management and analysis was performed using the IBM SPSS Statistics software version 20.0, (NY, IBM Corp.), the level of significance was set at 0.05 . The numbers and percentages were used to describe the frequencies of occupational health problems among the dentists. The answers to each type of occupational health problems were compared by sex, education level, years in service, type of practice sector, work pattern and the preferable work position, using Chi-square test.

\section{RESULTS}

Table 1 shows the demographic data, employment characteristics and education level of 340 Libyan dentists participated in the study with mean age in years $(35 \pm 8.4)$, over half of them were females $(51.5 \%)$, likewise $(52.8 \%)$ of the participants were working in private sector and $(52.1 \%)$ as full time employee. Forty percent of the participants had more than 10 years providing dental healthcare services and nearly $64 \%$ of the participating dentists holding a Bachelor of Dental Science (BDS) degree.

Table 2 presents the distribution and bivariate comparison of occupation health problems reported by participants. It can be seen that the most commonly reported occupational problem is musculoskeletal pain, followed by percutaneous injuries and eye problems $(48.2 \%, 35.3 \%$ and $22 \%$ respectively). Musculoskeletal problems were significantly higher among dentists who work in private sector, full timer as 
well as those who prefer to work in a sitting position ( $p=0.021,0.027$ and 0.008, respectively). Practitioners with less than 5 years in service reported significantly higher percentage of percutaneous injuries $(p=0.027)$ than their senior counterparts, whereas practitioners who spent more than 10 years in service and those who had got higher dental degrees were more likely to suffer from visual disturbances $(\mathrm{p}<0.001, \mathrm{p}=0.033$, respectively). Only a small number of respondents indicated that they had hearing problems $(11 \%)$ or allergy $(7.6 \%)$. Allergic reactions were more prevalent in females $(\mathrm{p}=$ 0.001 ) as well as dentists who are working in public health sector $(p<0.001)$. No significant differences were found among study subgroups in their experiences of hearing problem (Table 2).

\section{DISCUSSION}

The results of this study indicate that musculoskeletal problems, percutaneous injuries and sight problems, respectively, are the most commonly reported occupationrelated health problems among dentists, with at least one symptom reported by the a large number of the participants during the past 12 months. Another important finding was that the prevalence of the reported health problem may be influenced by the professional characteristics and work habits of dental practitioners.

These outcomes corroporate the results from previously conducted research. The relatively high percentage of dentists suffering musculoskeletal problems is comparable to the previously reported figures from different parts of the world, such as Australia, ${ }^{4}$ United Arab Emirates, ${ }^{8}$ Saudi Arabia ${ }^{11}$ and Denmark..$^{5}$ Similarly, few dentists reported hearing problems in this study which have also been the case in other previous studies. ${ }^{6,8}$ In contrast to earlier findings, this study throws out figures regarding percutaneous injuries and eye problems which differ from those reported in other countries. The reported statistics for percutaneous injuries were relatively lower than that reported in previous studies in United Arab Emirates ${ }^{8}$ and Thailand, ${ }^{6}$ yet it is higher than that observed in other countries such as Brazil ${ }^{12}$ South Africa ${ }^{13}$ and New Zealand..$^{14}$ Comparably, sight problems were lower than that observed in other Arabic countries, it is nearly half of that reported among dentists

Table 2: Numbers (percentages) for dentists with percutaneous injuries and musculoskeletal, allergy, hearing and eye problems in the last year $(n=340)$

\begin{tabular}{|c|c|c|c|c|c|}
\hline Variables & $\begin{array}{l}\text { Musculoskeletal } \\
\text { problems }\end{array}$ & $\begin{array}{l}\text { Percutaneous } \\
\text { injuries }\end{array}$ & Allergy & $\begin{array}{l}\text { Hearing } \\
\text { problems }\end{array}$ & $\begin{array}{l}\text { Eye } \\
\text { problems }\end{array}$ \\
\hline All sample & 164 (48.2) & 120 (35.3) & $38(11.2)$ & $26(7.6)$ & 77 (22) \\
\hline \multicolumn{6}{|l|}{ Sex } \\
\hline Men & $89(50.9)$ & $61(37.8)$ & $10(5.7)$ & $10(5.7)$ & $44(25.1)$ \\
\hline Women & 75 (45.5) & $59(33)$ & $28(17)$ & $16(9.7)$ & $33(20)$ \\
\hline p-value & 0.319 & 0.823 & $0.001^{* *}$ & 0.165 & 0.257 \\
\hline BDS & $99(60.4)$ & $78(45.8)$ & $24(11.1)$ & $12(5.6)$ & 41 (19) \\
\hline Higher degree & 65 (39.6) & $42(52.4)$ & $14(11.3)$ & 14 (11.3) & $36(29)$ \\
\hline p-value & 0.242 & 0.120 & 0.960 & 0.055 & $0.033^{*}$ \\
\hline \multicolumn{6}{|l|}{ Practice sector } \\
\hline Public & 67 (41.9) & $48(30)$ & 30 (18.8) & $8(5)$ & 34 (21.3) \\
\hline Private & $97(53.9)$ & $72(40)$ & $8(4.4)$ & $18(10)$ & $43(23.9)$ \\
\hline \multicolumn{6}{|l|}{ Years of service } \\
\hline $1-5$ years & 37 (22.6) & $32(41.1)$ & $8(8.9)$ & $6(6.7)$ & $18(20)$ \\
\hline $6-10$ years & $53(32.3)$ & $49(48.2)$ & $15(13.6)$ & $6(5.5)$ & $13(11.8)$ \\
\hline >10 years & $74(45.1)$ & 39 (58.8) & 15 (10.7) & $16(10)$ & $46(32.9)$ \\
\hline p-value & 0.222 & $0.023^{*}$ & 0.556 & 0.374 & $<0.001^{* * *}$ \\
\hline \multicolumn{6}{|l|}{ Work mode } \\
\hline Part time & $68(41.7)$ & $53(32.5)$ & $21(12.9)$ & $10(6.1)$ & $37(22.6)$ \\
\hline Full time & $96(54.2)$ & $67(37.9)$ & $17(9.6)$ & $16(6.9)$ & $40(22.7)$ \\
\hline p-value & $0.021^{*}$ & 0.304 & 0.338 & 0.314 & 0.982 \\
\hline \multicolumn{6}{|c|}{ Working position } \\
\hline Sitting & $19(73.1)$ & $14(53.8)$ & $2(7.7)$ & $4(15.4)$ & $6(23.1)$ \\
\hline Standing & $99(49.7)$ & $70(35.2)$ & $18(9)$ & $14(7)$ & $45(22.6)$ \\
\hline Both & $46(40)$ & $36(31.3)$ & $8(15.7)$ & $8(7)$ & $26(22.6)$ \\
\hline
\end{tabular}

Superscripts indicate where differences were located; ${ }^{*} \mathrm{p}: 0.05,{ }^{* *} \mathrm{p}: 0.01,{ }^{* * *} \mathrm{p}: 0.001 ;$ Chi-square test used to compare study subgroup 
in Saudi Arabia, ${ }_{11}^{11}$ and United Arab Emirates. ${ }^{8}$ Previous research has shown that the prevalence and location of musculoskeletal problems are influenced by posture and work habits, work station design, rest period during work as well as demographic factors. ${ }^{2,15-17}$ This study confirms the association between musculoskeletal problems among dental practitioners and working position as well as work load, where significantly different rates of musculoskeletal pain were reported when compared by preferred working position and work pattern. In the current study, full timers as well as dentists who usually work in sitting position were more likely to experience musculoskeletal pain than part timers and those who keep alternating between sitting and standing positions. It seems possible that these results are due to the nature of work in full time jobs where dentists are exposed to more job-related physical load and stress than did their peers who are part timers. This explanation is supported by previous findings that physical load is associated with musculoskeletal disorders. ${ }^{7}$ Furthermore, the static positions were found to be the most reasonable risk factors for musculoskeletal problems among dental hygienists, ${ }^{18}$ as they can result in ischemia and pain in the overworked muscles. ${ }^{19}$

The time spent in service is an important determinant for many occupational-related health problems. In our study, years of service were significantly associated with different levels of percutaneous injuries and sight problems. On one hand, the less experienced dentists were found to be at higher risk of getting injured during work than their experienced colleagues. Although this finding further support the idea of that newly graduated dental students are the most vulnerable of all health workers to such injuries, ${ }^{20}$ it contradicts reports from Brazil where older dentists are more prone to percutaneous injuries than young dental practitioners. ${ }^{12}$ It is not clear why this is but it might be related to less adherence to precautionary measures or inadequate training. ${ }^{12}$ On the contrary, reported eye problems were significantly prevalent in senior dental practitioners. It has been suggested that most eye problems are usually seen in the daily life and may not be occupationally related, however, they may affect the work of dentists or be aggravated by their occupation. ${ }^{6}$

In the present study, the prevalence of allergic symptoms was found to be higher among females than that in males which is in line with previous research. ${ }^{14,21}$ It is interesting to note that a significantly larger number of dentists working in the public sector claimed that they have had allergic reactions to different dental materials in the past year as compared to those working in private sector although allergic reactions are among the least reported occupational health problems in this study. This finding throw important question regarding the quality and composition of dental materials used in different health sectors.

This study's findings have important implications for developing more effective strategies to aid in prevention of occupationally related problems among dental staff. Dental practitioners may be advised to avoid working in sitting position and instead use alternate working positions. Another implication of this is the possibility that dental practitioners are not well prepared to apply preventive measures in order to avoid occupational hazards in dental practice. Dental education institutions are required to put more emphasis on the topics of occupational health, infection control and ergonomics in order to prepare dental students to face work-related threats. Further research using objective measures is required to investigate the incidence, nature and predisposing factors for occupational health problems and the impact of dental education on their prevalence.

To the authors' knowledge, this is the first study to explore such occupational health problems in Libyan dental practitioners. The findings of this study are based on self-reported questionnaire which is liable to recall bias and gives answers with respect to the occurrence of symptoms rather than their actual frequency or intensity. Despite this, the use of self-report through questionnaires is omnipresent in healthcare research and is believed to be reliable measure to collect data, except for the rare cases..$^{22}$ Although the response rate in the current study is very high, the lack of reliable data on registered dentists in Libya and the inoperative mail service in the country hindered conducting mail survey and consequently a wider distribution of the study sample. On the contrary, the in person distribution of questionnaires and the targeting of scientific meetings were considered as the most practical method to reach dentists in such countries. ${ }^{23}$

\section{CONCLUSION}

Musculoskeletal problems and percutaneous injuries were the most commonly reported problems by Libyan dentists. Young practitioners with less experience had higher risk to percutaneous injuries. In addition, practice habits, and work load were contributing factors to the incidence of musculoskeletal problems.

\section{ACKNOWLEDGMENT}

The authors are grateful to the dentists who participated in this study. 


\section{REFERENCES}

1. Scully C, Cawson R, Griffiths M. Ch. 3. Physical and chemical dangers in dentistry. Occupational Hazards to Dental Staff 1990. p. 55-98.

2. Leggat PA, Kedjarune U, Smith DR. Occupational health problems in modern dentistry: a review. Industrial Health 2007;45(5):611-621.

3. Hayes MJ, Smith DR, Taylor JA. Musculoskeletal disorders and symptom severity among Australian dental hygienists. BMC Research Notes 2013;6(1):250.

4. Leggat PA, Smith DR. Musculoskeletal disorders selfreported by dentists in Queensland, Australia. Aust Dent J 2006;51(4):324-327.

5. Finsen L, Christensen H, Bakke M. Musculoskeletal disorders among dentists and variation in dental work. Applied Ergonomics 1998;29(2):119-125.

6. Chowanadisai S, Kukiattrakoon B, Yapong B, Kedjarune $\mathrm{U}$, Leggat PA. Occupational health problems of dentists in southern Thailand. Int Dent J 2000;50(1):36-40.

7. Alexopoulos EC, Tanagra D, Konstantinou E, Burdorf A. Musculoskeletal disorders in shipyard industry: prevalence, health care use, and absenteeism. BMC Musculoskeletal Disorders 2006;7(1):88.

8. Al-Ali K, Hashim R. Occupational health problems of dentists in the United Arab Emirates. Int Dent J 2012;62(1):52-56.

9. Porter K, Scully C, Theyer Y, Porter S. Occupational injuries to dental personnel. J Dent 1990;18(5):258-262.

10. WHO. World Health Statistics 2013. Geneva: World Health Organization, 2013.

11. Al Wassan K, Almas K, Al Shethri S, Al Qahtani M. Back and neck problems among dentists and dental auxiliaries. J Contemp Dent Pract 2001;2(3):17-30.

12. Martins AMEBdL, Santos NC, Lima MÉDd, Pereira RD, Ferreira RC. Needlestick and sharp instrument injuries among dentists in Montes Claros, Brazil. Arquivos em Odontologia 2010;46(4):127-135.
13. Yengopal V, Naidoo S, Chikte U. Infection control among dentists in private practice in Durban, Kwazulu-Natal. J Dent Res 2001;80(3):1364.

14. Gibson G, Noble M, MacFadyen E. A pilot survey on compliance with recommended infection control procedures in ninety dental practices in New Zealand. Int Dent J 1995; 45(5):279.

15. Rundcrantz B, Johnsson B, Moritz U. Cervical pain and discomfort among dentists. Epidemiological, clinical and therapeutic aspects. Part 1. A survey of pain and discomfort. Swedish Dent J 1989;14(2):71-80.

16. Ratzon NZ, Yaros T, Mizlik A and Kanner T. Musculoskeletal symptoms among dentists in relation to work posture. Work: A Journal of Prevention, Assessment and Rehabilitation 2000; 15(3):153-158.

17. Damkot D, Pope M, Lord J, Frymoyer J. The relationship between work history, work environment and low-back pain in men. Spine 1984;9(4):395-399.

18. Åkesson I, Balogh I, Hansson G-Å. Physical workload in neck, shoulders and wrists/hands in dental hygienists during a work-day. Applied Ergonomics 2012;43:803-811.

19. Langford ML. Poor posture subjects a worker's body to muscle imbalance, nerve compression. Occupational Health and Safety (Waco, Tex) 1994;63(4):38-40.

20. Osazuwa-Peters N, Obarisiagbon A, Azodo CC, Ehizele AO, Obuekwe ON. Occupational exposure to sharp injuries among medical and dental house officers in Nigeria. Int J Occup Med Environ Health 2013;26(9):283-290.

21. Leggat PA, Smith DR. Prevalence of hand dermatoses related to latex exposure amongst dentists in Queensland, Australia. Int Dent J 2006;56(2):154-158.

22. Stone AA, Shiffman S, Schwartz JE, Broderick JE, Hufford MR. Patient non-compliance with paper diaries. BMJ 2002; 324(3774):1193-1194.

23. Ghasemi H, Murtomaa H, Torabzadeh H, Vehkalahti MM. Perceived barriers to the provision of preventive care among Iranian dentists. Oral Health and Preventive Dentistry 2009;7(4):339. 